\section{A MUST-ATTEND DIGITAL SYMPOSIUM}

Whether you are new to digital dentistry or a clinician with many years' experience, the CEREC Symposium, held on 27-28 March at the Royal College of Physicians in London, is the must-attend event for all.

Henry Schein Dental has put together an exciting speaker line-up, including CEREC Educator Bobby Chagger presenting 'The Digitalisation of Dentistry'; and Julian Caplan, Patrik Mofors, Ivan Ghandour, Nick Claydon and Simon Belford, who will present on a range of digital dentistry topics such as 'Anterior Aesthetics', 'CEREC Workflow', 'Hands-on Digital Impressions' and 'Implant Integration with CmG'. Colin Campbell will also talk about how CEREC has been easily integrated into his practice.

Hands-on learning zones will provide an opportunity to watch a range of demonstrations. In addition, the exhibition offers delegates the opportunity to see and experience the latest digital equipment in action. For those experienced CEREC practitioners who want to take the next step and perfect their skills to create lifelike, natural, same-day restorations, or who want to learn more about how to integrate CEREC with implant planning software, the Symposium provides ample opportunity to learn and to discuss options and techniques with experts in the digital arena.

Booking for the CEREC Symposium 2015 is £300. For more information call 02920442818 or email suzanne.clements@henryschein.co.uk.

\section{BETTER MARKETING INSIGHTS}

Dentally, the cloud-based web application for practice management, recently launched the ability for your marketing software to integrate with your practice data. This is enabled by a technology known as an 'application programming interface' (API). Popular cloud based companies like Twitter, Google and Facebook all have APIs that enable the development of apps that can integrate with their information-rich databases.

The Dentally API allows the marketing software that practices use to integrate with their practice data to provide an understanding of the path that lead someone to become a new patient of yours. This can indicate to the practice team the best channels to spend marketing time and money on to drive new patients to the practice. For example if you were promoting the practice on your blog, you could see which articles lead to the most new NHS patients or the most new private patients giving you insight on the best content to write for the type of patients you want to attract.

Find out more at www.dentally.co/bdj. Read more about integration at https://developer.dentally.co/.

\title{
CONSULT, LEARN AND GROW WITH NEW BUSINESS PROGRAMME AND EXPERT ADVICE
}

Business IQ is a new programme from Henry Schein Dental that will help practices understand how to develop more efficient business processes, improve communication and offer advice and guidance on a range of topics.

Business IQ is built around three key areas: Consult - Learn - Growth, and has established relationships with partners including Laura Horton Consulting, THRIVE from Software of Excellence and Finance4Patients among others. Via Business IQ, each partner will bring specific expertise across a range of disciplines, all aimed at improving process and profitability for dental practices.

No matter whether a practice requires team training or clinical education, Business IQ has a full programme that will help improve techniques and processes in practice. Those who want to make the most of the EXACT practice management software can access education via the Academy of Excellence, which provides individual staff training and practice performance programmes designed to improve efficiency and increase revenue.

Business IQ will help practices grow either by increasing revenue or by reducing costs. Help with marketing or practice and treatment promotion will help attract new patients and provide more appropriate services for existing patients. Keeping control of costs is important for every business and Business IQ has tips and advice on how to run the most efficient practice possible. Partners include Milkshake Dental Marketing and Initial Medical.

To find out more about Henry Schein Dental's new brand, Business IQ, visit www.hsbusinessiq.co.uk.

\section{TOOTHBRUSHING APP SHORTLISTED FOR AWARD}

The Brush DJ toothbrushing app has been shortlisted for the AXA PPP Health Tech and You Awards and will be exhibited at the Design Museum in March and April.

The NHS-approved app - which motivates users to brush for two minutes while listening to songs taken at random from their device or from a playlist of favourite tunes - is in the Health Tech \& You Keep Me Healthy shortlist.

Twenty-four shortlisted entries will be showcased at the Design Museum, taken from over 120 entries in six categories. Six judging panels will decide each category winner as well as an overall winner to be announced during an awards ceremony on 18 March 2015. https://www.healthtechandyou.com/

http://www.brushdj.com/

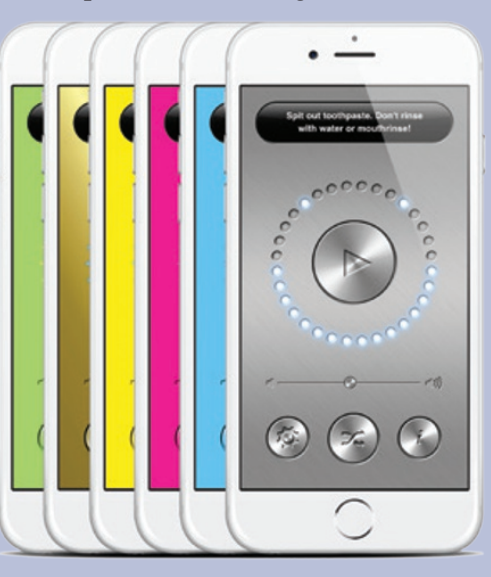

\section{GROW YOUR PATIENT BASE AND YOUR BUSINESS}

Artisan Lifecycle Marketing from 7connections is designed to help you attract new leads, nurture prospective leads and increase your referrals and provides a cost efficient and highly effective direct marketing solution.
It automatically tracks your conversation rates and measures your progress even when re-engaging with people months after their enquiries. For more information visit www.7connections.com/artisanroadshow or call 01647478145. 